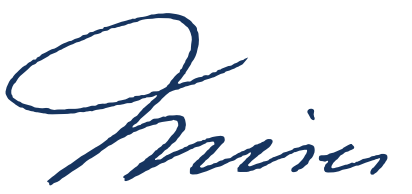

\title{
Uma análise sobre o tratamento das questões ambientais na tradição da Escola Austríaca
}

\author{
Paulo Hora Andrade III ${ }^{\text {I }}$ [D 0000-0002-3233-0587 \\ Universidade Federal do Paraná - Curitiba - Paraná - Brasil
}

\begin{abstract}
Resumo: O presente trabalho pesquisa o histórico da abordagem da escola austríaca em relação a problemas ambientais, desde o início dessa tradição (1871) até a atualidade (2021). Nessa pesquisa, observa-se que, após muitos anos de considerações apenas superficiais sobre o tema, o artigo Law, Property Rights, and Air Pollution, publicado por Murray Rothbard, em 1982, marcou o início da definição de um paradigma marcadamente austríaco, isto é, baseado na ontologia subjetivista, para os problemas ambientais, no que foi seguido por outros autores, com destaque para Roy Cordato e Graham Dawson. Mais adiante, no entanto, este artigo identifica os problemas que persistem para a formulação coerente dessa abordagem como contraponto à economia ambiental neoclássica e as limitações que sua natureza microanalítica impõe à formulação de um contraponto à economia ecológica.
\end{abstract}

Palavras-chave: escola austríaca, problemas ambientais, subjetivismo, economia ambiental neoclássica, economia ecológica.

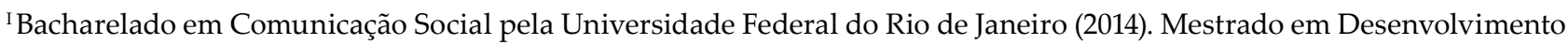
Econômico pela Universidade Federal do Paraná (2018). Licenciatura no Programa Especial de Formação de Docente pela Universidade Tecnológica Federal do Paraná (2019). E-mail: paulo_terceiro@hotmail.com.
} 


\title{
An analysis of the treatment of environmental issues in the Austrian school tradition
}

\begin{abstract}
This paper investigates the history of the Austrian school's approach to environmental problems, from the beginning of this tradition (1871) to the present time (2021). In this research, it is observed that, after many years of only superficial considerations on the subject, the article "Law, Property Rights, and Air Pollution", published by Murray Rothbard, in 1982, marked the beginning of the definition of a distinctly Austrian paradigm, that is, based on the subjectivist ontology, for environmental problems, which was followed by other authors, especially by Roy Cordato and Graham Dawson. Further on, however, this paper identifies the problems that persist for the coherent formulation of this approach as a counterpoint to neoclassical environmental economics and the limitations that its microanalytical nature imposes on the formulation of a counterpoint to ecological economics.
\end{abstract}

Keywords: environmental problems, subjectivism, neoclassical environmental economics, ecological economics.

\section{Un análisis del tratamiento de las cuestiones ambientales en la tradición escolar Austriaca}

\begin{abstract}
Resumen: Este artículo investiga la historia del enfoque de la escuela austriaca a los problemas ambientales, desde el inicio de esta tradición (1871) hasta la actualidad (2021). En esta investigación se observa que, luego de muchos años de consideraciones sólo superficiales sobre el tema, el artículo Law, Property Rights, and Air Pollution, publicado por Murray Rothbard, en 1982, marcó el inicio de la definición de un paradigma netamente austríaco, es decir, basado en la ontología subjetivista, para problemas ambientales, que fue seguido por otros autores, especialmente Roy Cordato y Graham Dawson. Más adelante, sin embargo, este artículo identifica los problemas que persisten para la formulación coherente de este enfoque como contrapunto a la economía ambiental neoclásica y las limitaciones que su naturaleza microanalítica impone a la formulación de un contrapunto a la economía ecológica.
\end{abstract}

Palabras clave: problemas ambientales, subjetivismo, economía ambiental neoclásica, economía ecológica. 


\section{Introdução}

A abordagem da escola austríaca para a economia é baseada em três princípios mais amplos: individualismo; subjetivismo; e visão do mercado como um processo. A partir dessa base, a história dessa escola de pensamento se desenvolveu com ênfase na defesa dos mecanismos de mercado, por meio do sistema de preços, e na defesa da instituição da propriedade privada.

Neste trabalho, verifica-se como tais fundamentos criaram dificuldades para que os principais expoentes da escola austríaca (Carl Menger, Eugen von Böhm-Bawerk, Friedrich von Wieser, Ludwig von Mises, Friedrich August von Hayek e Israel Kirzner) tratassem de problemas ambientais dentro da teoria econômica. Na seção 2, após a exposição do tratamento de tais questões de forma subordinada a outros temas mais amplos (coordenação, funcionamento do mercado e papel do governo, por exemplo) pelos autores acima, identifica-se em Murray Rothbard, outro grande expoente dessa escola de pensamento, a primeira tentativa mais explícita de considerar os problemas ambientais dentro do quadro analítico austríaco.

Nesse sentido, é argumentado que Rothbard e os autores que seguiram sua proposta para a consideração das questões ambientais, com destaque para Roy Cordato e Graham Dawson, cujos argumentos são expostos na seção 3, não consolidaram uma alternativa austríaca coerente para a abordagem ambiental neoclássica, pois o fundamento subjetivista é usado, em última instância, para negar a existência de problemas ambientais, em vez de para derivar possíveis formas de enfrentá-los.

Na seção 4, identifica-se em Dawson (2015) uma tentativa de generalizar o princípio subjetivista da escola austríaca para "agentes não humanos", de modo a considerar, além dos problemas colocados pela abordagem ambiental neoclássica, os colocados pela economia ecológica. Argumenta-se, na mesma seção, no entanto, que, na falta de um posterior desenvolvimento dessa proposta, que o autor promete para artigos futuros, não há indícios de que a abordagem austríaca possa oferecer uma alternativa aos problemas macroanalíticos colocados pela economia ecológica, enquanto, ainda que com as incoerências apontadas ao longo do presente trabalho, isso foi feito em relação à abordagem ambiental neoclássica.

\section{Tratamento Periférico da Questão Ambiental Entre os Principais Nomes da Escola Austríaca até A Publicação de Rothbard (2002)}

Nesta seção, o tratamento da questão ambiental ou de conceitos relacionados a ela, como externalidades e bens públicos, é buscado, de forma bastante resumida, nos escritos dos principais nomes associados à escola austríaca, desde sua fundação, em 1871, com o Grundsätze der Volkswirtschaftslehre, de Menger, até o artigo Law, Property Rights, and Air Pollution, publicado por Rothbard, em 1982.

A fim de se fazer uma breve menção às abordagens de Menger, Böhm-Bawerk e Wieser, os três mais antigos dentre os nomes de maior destaque da escola austríaca, opta-se aqui pela exposição feita por Cordato (1992a), em que é mostrado como os autores trataram de forma "implícita" sobre o fenômeno da externalidade e formaram a base da discussão mais explícita 
que seria feita por Mises. Nesse contexto, Cordato (1992a, p. 27) pontua que a análise econômica das externalidades surgiu com a publicação do Economics of Welfare, de Arthur Pigou, em 1920, anos depois dos principais trabalhos dos três mencionados pioneiros da escola austríaca, e que, por isso, as observações a respeito dos escritos destes sobre o tema envolvem "certa dose de conjectura e inferência".

De acordo com Cordato (1992a), Menger percebeu a existência de externalidades negativas como um problema que envolve o conflito no uso da propriedade por parte de diferentes agentes e que o sistema econômico não resolveria, enquanto as externalidades positivas só teriam consequências benéficas, como no caso da origem não intencional da instituição da moeda a partir de ações individuais que apenas visavam à obtenção de bens com maior grau de "vendabilidade" no mercado. Cordato (1992a) observa, então, que Menger, após diferenciar explicitamente "bens econômicos", sujeitos à escassez e que necessitam de propriedade privada, de "bens não econômicos", abundantes e que não necessitam de propriedade privada, admite que, em alguns casos, um bem pode estar no limite entre essas duas categorias, de modo que, a partir de certo ponto, o mau uso por parte de alguns indivíduos pode ser prejudicial a outros.

Cordato (1992a) observa que Menger não deu exemplos dessas situações intermediárias, mas entende que o problema de poluição do ar se encaixa nelas, argumentando que, com baixa poluição, o ar limpo não precisa de direitos de propriedade (bem não econômico), enquanto, a partir de certo nível de poluição (mau uso de um bem), passa a necessitar de direitos de propriedade (bem econômico). Já no caso de Böhm-Bawerk, apesar deste não tratar das externalidades negativas, Cordato (1992a) entende se tratar do mais explícito, entre os três autores em questão, a reconhecer o fenômeno da externalidade positiva, mas com o argumento de que os bens disponibilizados pelo Estado não formam uma categoria especial em relação aos produzidos pelo mercado no que diz respeito à possibilidade de beneficiar pessoas que não estão envolvidas em sua produção.

Cordato (1992a, p. 33) pontua que Böhm-Bawerk não discutiu a possibilidade de que os benefícios externos associados ao bem provoquem problemas de carona de tal modo que não seja possível produzi-lo em mercados privados, mas argumenta que "há indicações" de que Böhm-Bawerk tenha considerado esse problema como apenas uma das razões pelas quais um bem pode acabar não sendo produzido e que, assim, não merecesse uma consideração especial. Já nos escritos de Wieser, Cordato (1992a) percebe uma abordagem ainda mais indireta para a ideia de externalidades, pois aquele autor observou que a renda pública obedece a princípios diferentes da privada, que está relacionada à lei do preço, de modo que sua preocupação se referia a distinção em relação a meios (formas de pagamento), em vez de a fins (bens). No entendimento de Cordato (1992a), Wieser defendeu um papel para o Estado na provisão de bens econômicos, mas isso não derivou de qualquer preocupação com a natureza "pública" desses bens.

Considerando-se os trabalhos dos principais autores identificados com a tradição austríaca, foi apenas no extenso livro Human Action, publicado em 1949, que surgiu a primeira discussão explícita das externalidades e dos problemas ambientais. Nessa obra, Mises (1998) considera o problema dos "custos externos" (externalidades negativas) como um em que algumas pessoas 
agem de forma a impor parte dos custos de sua ação em outras. Como exemplo, Mises (1998) cita o caso em que um bem não é propriedade de ninguém e muitos indivíduos o utilizam sem considerar as desvantagens associadas a tal escolha. $\mathrm{O}$ autor identifica como certos modos de exploração causam problemas ambientais, como erosão do solo e extinção de espécies de árvores e animais, e os associa ao fato de que os custos externos de utilização futura desses recursos não entram nos cálculos de insumo e produto.

Nesse sentido, Mises (1998) observa que, quando o solo de qualidade ainda era abundante, as pessoas não se preocupavam com tais métodos predatórios de exploração, pois, ao perceberem retornos líquidos decrescentes, elas podiam buscar outros terrenos. Em contraste, acrescenta Mises (1998), foi apenas quando a densidade populacional chegou ao ponto de esgotar as possibilidades de se encontrarem novas terras de qualidade que as pessoas passaram a considerar o problema causado pelos métodos predatórios a que recorriam e, assim, consolidou-se a instituição da propriedade privada.

Nesse cenário, Mises (1998) pondera que a nova realidade não fez com que se eliminassem todos os custos externos, mas que isso não se deve a supostas deficiências inerentes ao sistema econômico baseado na propriedade privada. Segundo Mises (1998), trata-se de uma consequência de brechas existentes no sistema, que poderiam ser removidas por meio de uma reforma nas leis referentes à responsabilidade por danos infligidos e de uma remoção das barreiras institucionais que impedem a operação plena da propriedade privada.

No caso de "economias externas" (externalidades positivas), Mises (1998) argumenta não se tratar de uma simples inversão do caso dos custos externos. Para o autor, quando o resultado de uma ação não beneficia apenas o agente em questão, é possível que: 1) o agente considere as vantagens que obtém para si importantes a ponto de valer a pena suportar inteiramente os custos; 2) os custos em questão são tão altos que nenhum dos beneficiários os aceita de forma integral. Da mesma forma que, no primeiro caso, claramente não haveria problema, uma vez que o projeto em questão não deixou de ser executado, Mises (1998) entende que, no segundo caso, como em qualquer outro em que um projeto não é lucrativo porque os consumidores preferem a satisfação esperada pela realização de outros projetos a tal empreendimento, a provisão pública de ou o subsídio a os bens em questão, que necessariamente desloca recursos de atividades lucrativas, não se justifica.

Em seu Constitution of Liberty, publicado em 1960, Hayek (2014) não aborda diretamente a questão das externalidades, mas discute problemas ambientais em relação à necessidade de conservar recursos naturais. Quando argumenta que, muitas vezes, "costuma-se defender a conservação com base em um preconceito irracional", Hayek (2014, s/p) propõe que, mesmo no caso de recursos renováveis, pode ser recomendável, a fim de aumentar a renda social, "substituir cada recurso que está se esgotando por um novo, apto a prestar uma contribuição pelo menos igual para a renda futura", pois "nosso problema não é preservar tais estoques de uma única forma, mas sempre mantê-los de uma forma que melhor contribua para a renda total".

Ao tratar de casos em que a conservação é justificada, Hayek (2014) identifica instâncias em que os serviços proporcionados por um bem não podem ser precificados. Como exemplo, 
Hayek (2014, s/p) cita “a preservação das belezas naturais”. Assim, é apenas nos casos em que a preservação dos recursos é considerada como um fim em si mesmo e em que não há como mensurar a renda derivada de seus serviços que Hayek (2014) reconhece a necessidade de ação coletiva para conservação.

No Law, Legislation and Liberty, publicado em três edições nos anos de 1973, 1976 e 1979, Hayek aborda as questões ambientais do ponto de vista mais claramente associado ao conceito de externalidades. De acordo com Hayek ([1976] 1998), a efetividade da ordem de mercado depende de que, na maioria dos casos, os produtores possam determinar quem irá arcar com os custos e se aproveitar dos benefícios dos bens em questão. No entanto, observa Hayek ([1976] 1998, p. 109), em problemas como os da poluição do ar e da água, os cálculos feitos pelos indivíduos sobre os custos e benefícios relacionados a sua propriedade não consideram os "efeitos de vizinhança".

A partir disso, Hayek ([1979] 1998, p. 44), identifica o caso dos bens "coletivos", dentre os quais enumera "proteção contra a violência, epidemias e desastres naturais". Hayek ([1979] 1998, p. 44) argumenta, então, que a provisão desses tipos de bens necessita de um método que não seja a venda para usuários individuais ou pequenos grupos organizados de forma voluntária, de modo que, "quando grandes números estão envolvidos, ninguém irá contribuir sem estar seguro de que os outros também o farão". Com essa explicação padrão para a provisão de bens públicos, Hayek ([1979] 1998) conclui que a compulsão governamental é, em muitos casos, o único meio de fazer com que os indivíduos contribuam para a provisão de um bem que eles mesmos desejam.

Em Competition and Entrepreneurship, publicado em 1973, Kirzner cita o caso em que a fumaça emitida pela atividade produtiva de uma fábrica causa danos às propriedades vizinhas. Nesse cenário, observa Kirzner (2012, p. 200), “a análise ortodoxa do bem-estar conclui que o produto da fábrica será tal que os custos sociais na margem superam os benefícios sociais relevantes, já que o dano às casas não entra nos cálculos do produtor". Em oposição, Kirzner (2012, p. 200) pondera que "não fosse pelo fato de os custos de transação prejudicarem as transações entre os donos das casas e o produtor, os danos poderiam entrar nos cálculos do produtor".

Observa-se, assim, que a solução de Kirzner (2012) para esse tipo de problema ambiental é, como a de Mises (1998), baseada na delimitação mais eficiente de direitos de propriedade, recorrendo, no caso, ao conceito de "custos de transação". Além disso, o autor defende que a abordagem correta para esse tipo de problema não é a da computação de custos e benefícios privados e sociais, mas a da "coordenação". Segundo Kirzner (2012, p. 201), o que é relevante não são benefícios e custos cujo conhecimento, na verdade, está ausente, mas saber quais transações que não estão sendo feitas atualmente seriam concluídas e quais que estão sendo feitas não seriam concluídas caso os participantes do mercado "estivessem conscientes das atitudes uns dos outros".

Kirzner (2012) argumenta que essa abordagem levanta as questões de atividade empresarial que não são consideradas na economia neoclássica do bem-estar. Pode-se entender, então, que Kirzner (2012) reconhece os problemas ambientais relacionados ao fenômeno das externalidades 
negativas e, como Mises (1998), defende o aprimoramento dos direitos de propriedade, a fim de estimular a atividade empresarial de descoberta de oportunidades lucrativas e reduzir os custos de transação, como solução.

Diante da identificação de, em mais de um século de existência da escola austríaca de economia, um tratamento apenas das questões ambientais apenas de forma subordinada a temas mais amplos, os argumentos de Rothbard (2002) podem ser considerados como um ponto de inflexão entre os economistas dessa tradição e, ao mesmo tempo, a fonte de novas contradições na busca por uma síntese da consideração austríaca sobre tais questões. Com seu artigo voltado ao tratamento específico dos problemas de poluição do ar, Rothbard (2002, p.139-140) argumenta que, se o indivíduo A causa a poluição do ar que o indivíduo B respira e isso pode ser provado "acima de qualquer dúvida razoável", existe uma "agressão", cujos danos devem ser pagos de acordo com a "responsabilidade estrita", a não ser que A já estivesse poluindo o ar antes de a propriedade de B ter sido desenvolvida.

Para Rothbard (2002), no caso de A ter começado a poluir antes da chegada de B, uma lei justa tem de avisar B sobre as condições existentes, de modo que este teria de se adaptar a um ambiente poluído, em vez de o contrário ocorrer. Já no caso de A ter chegado depois, o autor argumenta ser preciso provar, acima de qualquer dúvida razoável, que a poluição causou danos a B quanto ao uso legítimo de sua propriedade. Observa-se ainda que, no que diz respeito a fenômenos macroeconômicos, como os causados por mudanças climáticas de fontes antropogênicas, Rothbard (2002 p. 161) defende que a culpa deve ser atribuída "a cada poluidor individual", mas, reconhecendo a dificuldade prática de isso ser feito, recorre a sua idealizada "sociedade libertária", em que, por exemplo, as estradas seriam propriedade privada, de modo que as emissões que invadem o ar limpo na propriedade de outros indivíduos seriam de responsabilidade legal do dono da estrada em questão.

Assim, Rothbard (2002, p. 161) usa o último exemplo para estabelecer a proposição geral de que, como nos casos em que se verifica a "tragédia dos comuns", a propriedade privada dos recursos pode resolver o problema das "externalidades". Mais do que apenas apontar o problema e enunciar sua solução geral, então, Rothbard (2002) enumera os princípios de "apropriação original" (homesteading) (p. 127) e "causalidade estrita" (p. 140) como os fundamentos para a resolução de problemas ambientais, notadamente mantendo as ideias de Mises (1998) e Kirzner (2012) sobre a subordinação da identificação de problemas ambientais a conflitos no uso de propriedade privada, mas também explicitando os princípios que devem determinar a existência de tais conflitos.

\section{A Abordagem da "Eficiência": Uma Tentativa de Síntese Austríaca}

Visando à formulação de uma síntese austríaca sobre o tratamento dos problemas ambientais na teoria econômica, Cordato (1992a) identifica, nos escritos de Kirzner (2012) um complemento à proposta de Rothbard, de modo que a eficiência econômica passa a ser associada à coordenação de planos individuais. Nessa interpretação, explica Cordato (1992a), em qualquer instante, um mercado eficiente se move em direção à completa coordenação 
de planos individuais, de modo que, em vez de o estado de equilíbrio, é o processo que está sendo julgado.

De acordo com Cordato (1992a), a preocupação de Kirzner (2012) é com a capacidade do mercado em comunicar conhecimento aos participantes, o que se deve à função social dos empresários em exercer seu estado de alerta para descobrir e explorar oportunidades de lucro. No caso das externalidades, Cordato (1992a) argumenta que, na estrutura kizneriana de bemestar, apenas nos casos em que for provocada uma descoordenação de planos individuais elas reduzirão o bem-estar social. Assim, em combinação com a proposta cuja fonte identifica em Kirzner (2012), Cordato (1992a) sugere a utilização do princípio que chama de "preferência demonstrada", identificado em Rothbard (2002), para identificar possíveis violações no uso de propriedade privada devido ao fenômeno das externalidades.

Em suma, Cordato (1992a) defende que a eficiência social seja julgada de acordo com a extensão em que os indivíduos podem perseguir seus próprios objetivos, na medida em que estes são revelados por meio de suas ações, da maneira mais consistente possível. Com esse critério, Cordato (1992a, p. 64) afirma que as questões de eficiência devem focar no "Arranjo Institucional Ideal", fundado na instituição da propriedade privada. Nesse sentido, para o autor, o impacto que as externalidades têm sobre níveis de preço e produção não pode ser o fator decisivo na avaliação de sua eficiência, visto que não há preços e quantidades eficientes determinados independentemente das atividades que os geram, e, portanto, o único julgamento válido é se os indivíduos são impedidos de formular e executar os planos que, na ausência desses efeitos externos, fariam a respeito do uso de sua propriedade.

Em sua revisão a Cordato (1992a), Vaughn (1993, p. 916) argumenta que a discussão do autor sobre um "Arranjo Institucional Ideal" é, "na melhor das hipóteses, superficial", uma vez que ele pouco discute sobre a origem dos direitos de propriedade ou sobre como eles são definidos ou identificados no mundo real. Para Vaughn (1993, p. 916), uma enunciação dos benefícios dos direitos de propriedade deveria apenas "abrir a discussão", em vez de "definila completamente".

Na discussão sobre bens públicos, Vaughn (1993) considera que Cordato (1992a) acaba negligenciando o problema quando apenas repete o truísmo de que o único motivo pelo qual um bem público não é produzido é o fato de que sua produção não é lucrativa para ninguém. Vaughn (1993) argumenta que, mesmo diante da natureza subjetiva dos custos e benefícios e da impossibilidade de se determinar a quantidade ótima de bens públicos, não se pode ignorar os problemas que esse tipo de bem coloca. Vaughn (1993), conclui, assim, que uma questão apropriada para ser colocada na estrutura analítica de Cordato (1992a) é sobre o tipo de arranjo institucional que permitiria aos indivíduos perseguir seus planos quando os bens que eles almejam são públicos.

Para os fins deste trabalho, a crítica de Vaughn (1993) é considerada precisa e pode ser considerada, até o momento, a lacuna que a abordagem austríaca sobre questões ambientais precisa preencher para se consolidar como uma alternativa coerente à economia ambiental neoclássica. 
Em uma série de outros artigos, sem explicitamente responder a essas críticas, Cordato (1992b; 1997; 1998; 1999; 2001; 2002; 2004) desenvolve seus argumentos em busca de uma síntese para a abordagem austríaca sobre a economia do bem estar, com especial atenção aos problemas das externalidades e, mais especificamente, às questões ambientais, tornando mais explícita sua base rothbardiana e acrescentando discussões de Hayek sobre o problema alocativo geral de uma economia de mercado e diferenças metodológicas entre as ciências sociais e as naturais. Seus argumentos em todos esses trabalhos podem ser resumidos nos seis seguintes pontos:

a) As discussões de Hayek ([1937] 1958; [1945] 1958; 1955) sobre a base subjetivista da ciência econômica e o problema do conhecimento tácito disperso invalidam o entendimento dos problemas ambientais a partir dos conceitos de externalidades, das medidas de bem-estar social e da análise de estados de equilíbrio ou resultados ótimos desejados.

b) As soluções propostas pela abordagem ambiental neoclássica de taxação de poluição ou determinação de cotas negociáveis de poluição, consideradas "baseadas no mercado" são, na verdade, ainda que abram mão do procedimento de "comando e controle", uma nova forma de se buscar as antigas soluções socialistas. Em qualquer caso, as preferências dos indivíduos são apenas um dado a ser considerado nas políticas impostas.

c) Esses casos mais típicos de políticas de taxas e permissões negociáveis para emissão de gases violam os legítimos direitos de propriedade, conforme os princípios da "apropriação original" e da prova de dano "acima de qualquer dúvida razoável", que são os mais apropriados para promover a eficiência econômica em uma abordagem focada no processo e na coordenação de planos individuais, independentemente de quaisquer resultados específicos.

d) Os problemas na delimitação e reforço dos direitos de propriedade não consistem em "falhas de mercado", mas em "falhas de governo" em estabelecer e manter um arranjo institucional apropriado. Sempre que tal fenômeno ocorrer, como nos casos de poluição, cabe aos tribunais apenas decidir quem é o dono da propriedade e se há dano a esta "acima de qualquer dúvida razoável", de modo que a solução por negociações entre proprietários possa ser obtida.

e) Na perspectiva de uma ciência econômica subjetivista, qualquer suposto "dano ambiental" não deve ser analisado como um problema em si, mas apenas em termos de possíveis perturbações impostas aos planos dos indivíduos afetados por tais danos quanto ao uso de sua propriedade.

f) No caso das medidas de combate às causas de problemas macroambientais, como o aquecimento global, a perspectiva austríaca subjetivista leva à conclusão de que não há como mensurar a relação entre custos e benefícios de se aderir a elas, pois seria necessário saber como os recursos direcionados a essas medidas seriam usadas pelos indivíduos caso elas não fossem implementadas. Não havendo, em cada uma dessas supostas causas, maneira de provar responsabilidade "acima de qualquer dúvida razoável", a conclusão normativa é que ninguém deve ser impedido de usar sua propriedade como bem entender. 
Além de Cordato, outro autor a dar destaque ao tratamento da questão ambiental dentro da tradição austríaca é Dawson (2009; 2011; 2013), que deu ênfase ainda maior ao problema das mudanças climáticas. Seus principais argumentos podem ser resumidos nos seis seguintes pontos:

a) O aquecimento global antropogenicamente causado é um caso de "conflito interpessoal" sobre o uso de propriedade privada, em vez de um de "falha de mercado";

b) A identificação da magnitude dos efeitos da ação humana, notadamente a emissão de gases que agravam o efeito estufa, sobre as mudanças climáticas está sujeita a uma "incerteza radical", em vez de a um "risco calculável". Assim, as decisões mediadoras dos conflitos gerados por tais mudanças têm de se basear na identificação de comportamentos mais ou menos potencialmente danosos à propriedade de outrem, ainda que a magnitude de tal dano não possa ser precisamente calculada;

c) A política de combate às mudanças climáticas deve ser privatizada, com a eliminação de todos os instrumentos de política governamental (taxas, subsídios, regulações e cotas negociáveis de poluição), a favor de decisões jurídicas sobre "responsabilidade estrita", sem precisar atribuir novos direitos de propriedade, pois seriam considerados os direitos que já existem, a partir dos princípios de "apropriação original" da propriedade e de prova de dano "acima de qualquer dúvida razoável";

d) Como, no caso das mudanças climáticas, as emissões de 'gases estufa' por parte das atividades de um indivíduo só se tornam causa do problema quando combinadas com a feita pelas atividades de outros indivíduos, o princípio do "efeito combinado" permite a responsabilização individual por contribuir para o efeito em questão, ainda que, isoladamente, não conseguisse gerá-lo;

e) As decisões por meio de tribunais estimulariam, por exemplo, a concorrência entre teorias sobre o nexo causal entre as emissões de gás carbônico e o aquecimento global, fornecendo novas bases para os casos seguintes. Nesse sentido, o litígio jurídico seria um "bem público", podendo, inclusive, ocorrer que a jurisprudência se mova para fora do país de origem, tornando desnecessária a ideia de um "governo mundial" para tratar desse tipo de problema;

f) Uma vez que se considera um cenário de efeitos negativos das emissões de gases que agravam o efeito estufa sobre as gerações futuras, calculados em termos monetários, não há acordo sobre a taxa de desconto a ser utilizada para "compensar" tais gerações por esses danos.

A partir do exame desses argumentos, é notório que Dawson se propõe a aperfeiçoar a proposta de Cordato de explicitar um entendimento austríaco sobre a inserção dos problemas ambientais na teoria econômica. Em particular, ao reconhecer a dificuldade que a "incerteza radical" sobre os efeitos da emissão dos gases que contribuem para o efeito estufa sobre o aquecimento global coloca sobre a proposta de resolução jurídica dos conflitos a partir do 
princípio de prova de dano "acima de qualquer dúvida razoável", Dawson (2009; 2011; 2013) recorre a uma espécie de "compromisso de meio termo", que consiste na estimativa científica a respeito das chances de certas atividades produtivas provocarem mudanças climáticas e de estas provocarem fenômenos que violem a propriedade de certos indivíduos, de modo que o conceito de "responsabilidade estrita" seria adaptado a uma identificação de um comportamento de risco convencionalmente especificado.

Observa-se, então, que, a partir dos trabalhos de Cordato e Dawson, o estado atual da discussão econômica austríaca sobre os problemas ambientais tem base fortemente rothbardiana, contando também com argumentos descontextualizados de Hayek ([1937] 1958; [1945] 1958; 1955) sobre o uso do conhecimento disperso na sociedade e as diferenças metodológicas entre as ciências sociais e as naturais. Nesse sentido, os pilares da abordagem austríaca para problemas ambientais permanecem sendo os defendidos por Rothbard (2002), a saber, a prova de responsabilidade por dano "acima de qualquer dúvida razoável" e a "apropriação original".

\section{Economia Ecológica e Economia Austríaca: Um Diálogo Limitado A Priori}

Para entender a limitação da possibilidade de a abordagem ambiental austríaca dialogar com a da economia ecológica, a presente seção se inicia com uma breve exposição dos conceitoschave desta última tradição, com destaque às definições de "mundo cheio" e "sustentabilidade forte".

Quanto à definição de "mundo cheio", recorre-se aqui a Andrade, Romeiro e Simões (2012), que caracterizam o atual "mundo cheio" como um em que o capital natural é um fator escasso e limitante do desenvolvimento econômico, o que justifica um enfoque da política econômica que procure compatibilizar o desenvolvimento econômico com a preservação das condições de vida para gerações atuais e futuras. Nesse particular, é interessante observar que a discussão de Mises (1998) sobre o processo histórico de surgimento da propriedade privada, citada na seção 2, remete exatamente a essa ideia de "mundo cheio", mas, como visa apenas à justificação da instituição da propriedade privada, não deriva disso as discussões macroanalíticas propostas pela economia ecológica.

Nota-se ainda que, por meio de sua menção à arbitrariedade de qualquer taxa de desconto intertemporal utilizada para medir a gravidade de um aumento médio na superfície da Terra em datas futuras, a citada objeção de Dawson (2013) a políticas que visem à prevenção de mudanças climáticas, cujos resultados só incidiriam sobre gerações futuras, é uma derivação lógica de uma abordagem microanalítica fundada na suposição de direitos de propriedade bem delimitados e reforçados de acordo com o princípio da "apropriação original", o que, logicamente, deslegitima reivindicações de direitos de gerações futuras. Em contraposição, a economia ecológica assume a preservação das condições de vida para gerações futuras como um fim em si mesmo, sem depender de considerações de direitos de propriedade, de forma que objetivos referentes a, por exemplo, temperaturas médias desejadas para períodos 
determinados podem ser determinadas a partir de estimativas científicas e construção de consensos de cunho moral. (SMITH, 2001)

Já quanto ao conceito de "sustentabilidade forte" usado na economia ecológica, Dietz e Neumayer (2007) argumentam se tratar do reconhecimento de que o capital natural não é inteiramente substituível pelo capital humano ou pelo capital produzido, pois, além da função de prover matérias-primas para produção e consumo direto, em que há considerável possibilidade de substituição, há as funções de assimilar os resíduos da produção e do consumo e prover serviços de mitigação, em que a possibilidade de substituição é menor, e de prover as funções básicas de suporte à vida humana, considerada insubstituível. Em oposição, argumentam os autores, a economia ambiental neoclássica se baseia na "sustentabilidade fraca", em que os recursos naturais são apenas um fator de produção entre outros em modelos agregativos que determinam um uso ótimo para a renda gerada da extração do recurso e derivam regras sobre quanto consumir de e investir em capital produzido e humano para compensar a perda de capital natural.

Outras explicações úteis para o entendimento da abordagem da economia ecológica podem ser encontradas em Costanza (1989), que a caracteriza como uma atitude de "pessimismo tecnológico" (p. 2), isto é, de considerar que o avanço tecnológico não propiciará a superação das restrições fundamentais de recursos e energia, de modo que, eventualmente, o crescimento econômico irá parar. De acordo com Costanza (1989), ainda que não se saiba exatamente qual é o limite do ecossistema, a atitude adequada a uma estratégia de "maximizar o pior resultado possível" (p. 4) é adotar uma política de conservação dos recursos naturais no presente, visto que os 4 cenários são:

a) Pessimismo infundado perante a realidade futuramente revelada e adoção de uma política de conservação ambiental: o resultado será "desenvolvimento moderado";

b) Pessimismo infundado perante a realidade futuramente revelada e não adoção de uma política de conservação ambiental: o resultado será "desenvolvimento alto";

c) Pessimismo correto perante a realidade futuramente revelada e não adoção de uma política de conservação ambiental: o resultado será "desenvolvimento desastroso";

d) Pessimismo correto perante a realidade futuramente revelada e adoção de uma política de conservação ambiental: o resultado será "desenvolvimento tolerável";

Portanto, para, na pior das hipóteses, obter um "desenvolvimento tolerável”, Costanza (1989) defende uma política de conservação dos recursos naturais no presente. Do mesmo modo, Costanza (2020, p. 3) defende que se procure assegurar o bem estar sustentável "sob alto nível de incerteza", inerente a "sistemas complexos que envolvem processos irreversíveis", o que, segundo o autor, pode ser feito conservando e investindo em ativos de capital natural de modo equilibrado com os investimentos em capital humano e produzido.

Costanza (2020) identifica ainda que, apesar de seu artigo de 1989 ter a possibilidade de ser considerado como um dos pioneiros da abordagem da economia ecológica, cujo marco é 
a publicação da primeira edição da revista Ecological Economics naquele ano, verificam-se, em um passado mais distante, outras abordagens para o problema ambiental que levam em conta os limites para o crescimento, como o The Economics of the Coming Spaceship Earth, publicado em 1966, de Kenneth E. Boulding. Nesse artigo, observa Costanza (2020, p. 1), a descrição da transição da "economia de fronteira", em que o crescimento no bem estar implica crescimento do consumo, para a "economia da espaçonave", em que o crescimento do bem estar deve focar no bem estar sustentável da "espaçonave Terra", "preparou o terreno" para a economia ecológica.

Essa atitude distinta da economia ecológica em relação à economia ambiental neoclássica cria maiores dificuldades para que a abordagem austríaca possa oferecer uma alternativa, pois trata de problemas diferentes ou dos mesmos problemas em um nível distinto, isto é, o macroanalítico. Nos artigos e livros de Cordato e Dawson, anteriormente citados neste trabalho, não há menção à economia ecológica, mas apenas à economia ambiental neoclássica. Nesse sentido, destaca-se aqui a menção de Dawson (2015) a essa abordagem mais recente para questões ambientais.

De acordo com Dawson (2015), uma economia verde que vise ao entendimento da atividade econômica e a valorizar a natureza não humana deve dispensar a metodologia científica. Nesse sentido, Dawson (2015, p. 316) afirma que, ao impor "os valores do observador", tanto a economia ambiental neoclássica quanto a economia ecológica "falham em capturar a centralidade dos significados subjetivos dos agentes". No artigo em questão, diferentemente dos anteriores, o objetivo do autor vai além de defender praticamente os mesmos princípios propostos por Rothbard e Cordato para um entendimento austríaco do tratamento de questões ambientais na teoria econômica, pois ele passa a advogar uma "economia verde libertária", capaz de estabelecer prescrições normativas sobre uma natureza não humana possuidora de direitos de propriedade.

A partir disso, Dawson (2015) estende suas objeções anteriores à abordagem ambiental neoclássica à da economia ecológica. Após explicar que a característica que diferencia esta última da primeira é a negação de que sempre é possível substituir o capital natural por capital produzido ou humano e a consequente constatação de que há limites físicos para o crescimento econômico, Dawson (2015, p. 319) critica a abordagem da economia ecológica por "situar a economia no mundo físico", de modo a considerar, por exemplo, uma firma como um organismo que interage com outros, utiliza recursos e emite resíduos.

Para Dawson (2015, p. 320), a abordagem da economia ecológica falha ao não perceber que "inserir a economia na ecologia muda ambas", pois, nessa nova combinação, devem se situar "inovação, evolução cultural, mudança tecnológica e atividade empresarial". Assim, argumenta Dawson (2015, p. 320), “devemos nos mover da 'espaçonave terra' para a estação espacial internacional, que não permanece constante como um conjunto finito de recursos, mas se expande". No entendimento de Dawson (2015, p. 321), a abordagem da economia ecológica não deixa espaço para a agência humana, pois os fluxos de energia só deveriam importar "na medida em que afetam o bem estar e os direitos de propriedade de criaturas sensíveis e capazes de ter experiências". 
É, então, a partir de suas críticas à economia ambiental neoclássica e à economia ecológica, no que entende como suas falhas em aderir à perspectiva subjetivista, que Dawson (2015, p. 324) defende uma "economia verde libertária", que, no entendimento do autor, também se diferencia da economia ambiental austríaca até então existente. Na abordagem que propõe, Dawson (2015) propõe que a abordagem ambiental austríaca se estenda para incorporar a natureza não humana na consideração dos direitos de propriedade.

Nesse sentido, em tom de discordância, Dawson (2015) cita a afirmação de Cordato (2004) segundo a qual o meio ambiente consiste em apenas recursos físicos de produção, para propor que a economia verde libertária seja formulada com base na ideia de que planos e experiência não são atributos exclusivamente humanos. Da mesma forma, Dawson (2015) critica o conceito de eficiência defendido por Cordato (1992a) por se basear apenas na ação do tipo empresarial, isto é, voltada à obtenção de lucro monetário. De acordo com Dawson (2015, p. 328), tal parâmetro falha em reconhecer a variedade de atividades econômicas e, assim, a rejeição deste "facilita a extensão dos direitos de propriedade para animais não humanos com base no respeito por sua experiência subjetiva".

Diante dessa proposta visivelmente distinta das discussões que desenvolve em artigos anteriores, Dawson (2015, p. 328) reconhece ser necessário, em artigos futuros, mostrar como sua proposta de estender aos animais a posição de agentes donos de direitos de propriedade pode ser feita e como isso seria um "passo adiante em direção a uma formulação completa da economia verde libertária", de modo a combinar "a consideração de todos os aspectos da natureza humana e não humana com uma crença na superioridade dos mercados livres e de um estado mínimo".

No entanto, até a finalização do presente trabalho, essas tarefas complementares não foram feitas, de modo que se considera aqui que Dawson (2015) não apresenta, por inteiro, uma proposta de mudança na teoria ambiental austríaca, desenvolvida principalmente por Cordato e pelo próprio Dawson. O que chama mais a atenção no artigo de 2015 é o reconhecimento da abordagem da economia ecológica como novo "adversário", uma vez que, com base em Rothbard (2002), a abordagem austríaca de Cordato e Dawson já havia estabelecido sua posição subjetivista como fonte das críticas ao tratamento neoclássico sobre bem estar econômico, externalidades e problemas ambientais.

Observa-se aqui, no entanto, que, apesar de dirigir suas críticas a uma abordagem macroanalítica, isto é, à economia ecológica, Dawson (2015) mantém, como não poderia deixar de fazer dentro de uma perspectiva subjetivista, o caráter microanalítico da tradição austríaca em sua proposta de "economia verde libertária", baseada nos direitos de propriedade. Para o diálogo com a economia ambiental neoclássica, também predominantemente microanalítica, essa escolha pode ser frutífera para consolidar um paradigma alternativo, apesar de a base rothbardiana evitar a consideração dos problemas ambientais associados a externalidades e bens públicos, praticamente negados ex ante, a partir do critério da "preferência demonstrada".

Contudo, no caso da economia ecológica, predominantemente macroanalítica, mesmo que se reconheçam os mesmos problemas de depleção do meio ambiente, quando esta traz consequências negativas para "agentes não humanos", o diálogo não pode avançar além da 
exposição dos princípios básicos. Enquanto a economia ecológica considera os limites biofísicos da Terra como um impedimento para o crescimento ilimitado, a economia ambiental austríaca, mesmo com a adaptação sugerida por Dawson (2015) para incluir "agentes não humanos", considera a possibilidade de "expansão" dos recursos naturais mediante mudanças nas considerações subjetivas sobre eles, o que abre a possibilidade de sempre haver "descoberta". A partir dessa diferença, não faz sentido argumentar a favor da instituição dos direitos de propriedade e da base subjetiva de custos e benefícios, diante dos argumentos da economia ecológica, pois esta tem base holística, enquanto as abordagens ambientais austríaca e neoclássica têm base individualista.

\section{Conclusão}

Diante da identificada limitação na possibilidade de diálogo entre a abordagem ambiental austríaca e a da economia ecológica, nota-se que, curiosamente, ambas usam o conceito de "incerteza" para se diferenciar do paradigma ambiental neoclássico, que é baseado no pressuposto do equilíbrio geral perfeitamente competitivo como meta de política. No entanto, enquanto os austríacos entendem a presença da incerteza de modo microanalítico, para ressaltar o caráter subjetivo dos custos e benefícios e, portanto, invalidar as conclusões normativas derivadas de comparações interpessoais ou intertemporais de bem estar, os economistas ecológicos a entendem de modo macroanalítico, para ressaltar os desconhecidos limites do sistema ecológico que dá suporte às atividades econômicas. Assim, do ponto de vista da economia ecológica, a abordagem austríaca compartilha dos pressupostos neoclássicos de "sustentabilidade fraca", em que o capital natural pode ser substituído pelo produzido ou pelo humano, e de "economia da fronteira", em que o crescimento no bem estar implica crescimento do consumo.

Conforme exposto na seção 4, os argumentos de Dawson (2015) são uma tentativa isolada de oferecer alternativas à economia ecológica a partir da abordagem austríaca, com a notável proposta do autor em compatibilizar a proteção ambiental além da comprovada utilidade para o consumo humano com os pressupostos de defesa dos direitos de propriedade e de bem estar individual subjetivamente determinado. No caso, porém, Dawson (2015) reconhece que tal proposta de uma "economia verde libertária" ainda precisa ser desenvolvida. De qualquer forma, a abordagem microanalítica que fundamenta a investigação austríaca em direitos de propriedade e preferências subjetivas é capaz de proporcionar uma clara alternativa à abordagem ambiental neoclássica, mas dificilmente avança na discussão com a economia ecológica além do que foi feito por Dawson (2015).

Observa-se ainda que, desde a apresentação, em 1960, dos argumentos de Hayek (2014) sobre a possibilidade de a depleção de recursos naturais ser vantajosa do ponto de vista econômico, devido à possibilidade de substituí-los por outros recursos, sejam eles naturais, produzidos ou humanos, de igual ou maior valor, não houve outra discussão dentro da abordagem austríaca sobre tal questão. Dessa forma, entende-se aqui que essa conclusão, crucial para o entendimento neoclássico do problema ambiental microanalítico (SOLOW, 1974) e para a crítica da economia ecológica quanto à "sustentabilidade fraca", é implicitamente aceita 
pela discussão subsequente dos autores ligados à tradição austríaca, notadamente Rothbard, Cordato e Dawson.

Mais especificamente sobre o modo com que a abordagem austríaca se opõe à neoclássica sobre problemas ambientais, verifica-se que a primeira dispõe dos fundamentos necessários para oferecer uma alternativa consistente à segunda, mas acaba prejudicando sua própria base subjetivista para custos e benefícios quando advoga uma capacidade inquestionavelmente superior de o sistema de preços maximizar o bem estar social, em um arranjo institucional de propriedade privada bem delimitada e reforçada, em relação a qualquer política que não se origina no mercado, como as soluções de taxação e determinação de cotas negociáveis de poluição. Tal conclusão deriva diretamente do princípio da "preferência demonstrada", mas não necessariamente de uma consideração subjetivista de custos e benefícios.

Em contraponto, observa-se que o entendimento, essencial para o paradigma austríaco, de que a mudança é inerente à passagem do tempo, em um cenário de incerteza radical, invalida a ideia de que, a priori, o livre mercado promove a resolução mais eficiente dos conflitos no uso da propriedade, como os problemas ambientais. Na verdade, tal insistência de parte da abordagem austríaca em ignorar essa questão quando o assunto é o meio ambiente remete a um apego excessivo ao raciocínio que Mises e Hayek desenvolveram no contexto do debate do cálculo econômico socialista (BARBIERI, 2013) com vista à solução do problema alocativo mais geral, o que não necessariamente se estende a todos os problemas ambientais.

Como ilustração final deste ponto, expõe-se aqui o pós-escrito de Salerno (1990) ao artigo Economic Calculation in the Socialist Commonwealth, publicado por Mises em 1920, e que marcou o início do citado debate do cálculo econômico socialista. De acordo com Salerno (1990, p. 68), as políticas ambientais estão "se tornando progressivamente mais amplas em seu escopo e mais draconianas em seu reforço". Para o autor, "à medida que tais políticas avançam além da proteção dos direitos individuais, elas se tornam antissociais e destrutivas de capital e de padrões de vida" (p. 68). Na opinião de Salerno (1990, p. 68), então, "as regulações completas e centralizadas que alguns ambientalistas fanáticos estão defendendo são equivalentes à abolição da propriedade privada", de forma que, ao se levar esse fato em conta, "a conexão entre ambientalismo e socialismo fica ainda mais forte".

Fica claro, nesses trechos, que as questões ambientais colocadas pelo reconhecimento de externalidades e bens públicos a partir do ponto de vista dos próprios indivíduos envolvidos em uma situação de problema econômico que vai além da ação individual, isto é, de como alocar os meios existentes para um fim coletivamente compartilhado, é prejudicada por tal associação entre o problema alocativo geral em uma cataláxia e a resolução de problemas ambientais específicos, assim como o é a construção coerente de uma alternativa austríaca ao paradigma neoclássico.

\section{Referências}

ANDRADE, Daniel Caixeta; ROMEIRO, Ademar Ribeiro; SIMÕES, Marcelo Silva. From an empty to a full world: a nova natureza da escassez e suas implicações. Economia e Sociedade, v. 21, p. 695-722, 2012. 
BARBIERI, Fábio. História do debate do cálculo econômico socialista. Instituto Ludwig von Mises Brasil: São Paulo, 2013.

COSTANZA, R. Ecological economics in 2049: Getting beyond the argument culture to the world we all want. Ecological Economics, v. 168, n. Special Edition, p 1-5, 2020.

COSTANZA, R. What is ecological economics?. Ecological Economics, v. 1, n. 1, p. 1-7, 1989.

CORDATO, Roy E. Global Warming, Kyoto, and Tradeable Emissions Permits: The Myth of Efficient Central Planning. Institute for Research on the Economics of Taxation, 1999.

CORDATO, Roy E. Knowledge problems and the problem of social cost. Journal of the History of Economic Thought, v. 14, n. 2, p. 209-224, 1992b.

CORDATO, Roy E. Market-based environmentalism and the free market: they're not the same. The Independent Review, v. 1, n. 3, p. 371-386, 1997.

CORDATO, Roy E. The impossibility of harming the environment. Ideas on Liberty, v. 52, p. 15-17, 2002.

CORDATO, Roy E. The polluter pays principle: a proper guide for environmental policy. Institute for Research on the Economics of Taxation, 2001.

CORDATO, Roy E. Time passage and the economics of coming to the nuisance: Reassessing the Coasean perspective. Campbell L. Rev., v. 20, p. 273-292, 1998.

CORDATO, Roy E. Toward an Austrian theory of environmental economics. The Quarterly Journal of Austrian Economics, v. 7, n. 1, p. 3-16, 2004.

CORDATO, Roy E. Welfare economics and externalities in an open ended universe: A Modern Austrian Perspective. Springer Science \& Business Media: New York, 1992a.

DAWSON, Graham. Austrian economics and climate change. The review of Austrian economics, v. 26, n. 2, p. 183-206, 2013.

DAWSON, Graham. Free markets, property rights and climate change: how to privatize climate policy. Libertarian Papers, v. 3, p. 1-29, 2011.

DAWSON, Graham. Green economics, science and libertarianism. International Journal of Green Economics, v. 9, n. 3-4, p. 316-329, 2015.

DAWSON, Graham. Privatising climate policy. Economic Affairs, v. 29, n. 3, p. 57-62, 2009.

DIETZ, S.; NEUMAYER, E. Weak and strong sustainability in the SEEA: Concepts and measurement. Ecological Economics, v. 61, n. 4, p. 617-626, 2007.

HAYEK, Friedrich. Economics and knowledge, 1937. IN: HAYEK, Friedrich A. Individualism and economic order. University of Chicago Press: Chicago, 1958.

HAYEK, Friedrich. The use of knowledge in society, 1945. IN: HAYEK, Friedrich A. Individualism and economic order. University of Chicago Press: Chicago, 1958.

HAYEK, Friedrich A. Law, Legislation and Liberty Vol. 2: The Mirage of Social Justice, 1976. IN: HAYEK, Friedrich A. Law, Legislation and Liberty. Routledge: London, 1998.

HAYEK, Friedrich A. Law, Legislation and Liberty. The Political Order of a Free People. IN: HAYEK, Friedrich A. Law, Legislation and Liberty. Routledge: London, 1998. 
HAYEK, Friedrich A. Os Fundamentos da Liberdade. Visão: São Paulo, 2014.

HAYEK, Friedrich A. The Counter-Revolution of Science: Studies on the Abuse of Reason. The Free Press of Glencoe Collier-Macmillan Limited: London, 1955.

KIRZNER, Israel M. Competição e atividade empresarial. Tradução de Ana Maria Sarda. Instituto Ludwig von Mises Brasil: São Paulo, 2012.

MISES, Ludwig von. Human action. Ludwig von Mises Institute: Auburn, 1998.

ROTHBARD, Murray N. Law, property rights, and air pollution. Ludwig von Mises Institute: Auburn, 2002.

SALERNO, J. Postscript to economic calculation in the socialist commonwealth. In: Mises, Ludwig von. Economic Calculation in the Socialist Commonwealth. Ludwig von Mises Institute: Auburn, 1990.

SMITH, V. K. Environmental Economics. IN: SMELSER, Neil J. et al. (eds.). International encyclopedia of the social \& behavioral sciences. Amsterdam: Elsevier, 2001.

SOLOW, R. M. The Economics of Resources or the Resources of Economics. The American Economic Review, v. 64, n. 2, p. 1-14, 1974.

VAUGHN, Karen I. Welfare Economics and Externalities in an Open Ended Universe: A Modern Austrian Perspective by Roy E. Cordato: Reply. Public Choice, v. 77, n. 4, p. 915-917, 1993.

RECEBIDO: 08 DE AGOSTO DE 2021. APROVADO: 18 DE OUTUBRO DE 2021. 